\title{
Coxiella burnetii seroprevalence in primiparous and multiparous ewes from southern Australia: a cross- sectional study
}

\section{Thomas Clune}

Murdoch University

Amy Lockwood

Murdoch University

Serina Hancock

Murdoch University

Andrew N. Thompson

Murdoch University

Mieghan Bruce

Murdoch University

Susan Beetson

Murdoch University

Angus $\mathrm{J}$ Campbell

University of Melbourne

Elsa Glanville

University of Melbourne

Daniel Brookes

University of Melbourne

Colin Trengove

University of Adelaide

Caroline Jacobson ( $\sim$ c.Jacobson@murdoch.edu.au )

Murdoch University

\section{Research Article}

Keywords: Coxiella burnetii reservoir, Q-fever, lamb survival, lamb mortality, maiden ewe, reproduction

Posted Date: October 28th, 2021

DOI: https://doi.org/10.21203/rs.3.rs-1026866/v1 
License: (c) (i) This work is licensed under a Creative Commons Attribution 4.0 International License. Read Full License

Version of Record: A version of this preprint was published at Comparative Immunology, Microbiology and Infectious Diseases on November 30th, 2021. See the published version at https://doi.org/10.1016/j.cimid.2021.101727. 


\section{Abstract}

Coxiella burnetii can cause reproductive disease in sheep and zoonotic Q-fever infections in humans. The role of infectious diseases including coxiellosis in causing poorer reproductive performance of primiparous ewes is not well studied. The aim of this study was to determine if natural exposure to $C$. burnetii is associated with poor reproductive performance of primiparous ewes and compare seroprevalence of primiparous and multiparous ewes. Coxiella burnetii seroprevalence was $0.08 \%$ (95\% confidence interval $0.01,0.36)$ in primiparous ewes and $0.36 \%(0.07,1.14)$ in mature ewes. Coxiella burnetii was not detected in tissue samples from aborted or stillborn lambs using molecular diagnostic tests (qPCR). These findings suggest that $C$. burnetii infection was unlikely to be an important contributor to abortion and perinatal mortalities observed for primiparous ewes, and exposure to $C$. burnetii was not widespread in ewes on farms located over wide geographical region of southern Australia.

\section{Introduction}

The reproductive performance of primiparous ewes is often lower than that observed for multiparous ewes [1-3]. Higher incidence of foetal or lamb mortality from pregnancy diagnosis to lamb marking has been reported for primiparous ewes compared to multiparous ewes [2-4]. However, the causes of losses that occur during this period are not well defined. A number of endemic diseases may cause abortion and poor viability of lambs in Australia [5, 6]. It is not clear if infectious diseases are an important contributor to foetal and lamb mortality for primiparous ewes in Australia.

Coxiella burnetii is endemic in Australian livestock, including sheep, but prevalence and impact on sheep health is not well studied [7]. Infections in sheep can be asymptomatic, but in pregnant ewes can cause abortion, stillbirth and the birth of weak lambs that are less likely to survive [8-12]. The outcome of infection in the pregnant ewe may be influenced by strain virulence, severity of placental infection, and maternal and foetal immunity [13]. Abortions are more likely to occur during gestation following primary infection, with no lasting impacts on reproduction in subsequent pregnancies $[10,14]$. Therefore, younger ewes that are immunologically naïve are at risk of abortion if infection occurs during pregnancy.

Seroprevalence for $C$. burnetii in Australian sheep has been reported to range from $0-18.7 \%$ depending on the location, serological assay and cut-off values used [7, 15-18]. However, most of these studies are either over 50 years old or localised to specific regions or single farms. Consequently, the prevalence of $C$. burnetii for the current Australian sheep population is poorly quantified and the impact of $C$. burnetii on the reproductive performance of Australian sheep has not been assessed.

Apart from impacts for sheep health and production, $C$. burnetii has important zoonotic implications. Australia has one of the highest rates of human Q-fever cases reported globally $[19,20]$. Livestock are considered to be an important reservoir for infection in humans [21, 22]. Improved understanding of the role of sheep as a potential source of $C$. burnetii infections will inform recommendations for managing Q- 
fever risk in susceptible people including occupational risks for farmers, veterinary staff and abattoir workers $[23,24]$.

The aim of this study was to (i) determine if $C$. burnetii exposure is associated with poor reproductive performance of primiparous ewes in southern Australia, (ii) compare seroprevalence of primiparous and multiparous ewes and (iii) determine if ewes represent an important reservoir for $C$. burnetii infection in humans. We hypothesised that (i) $C$. burnetii infection and seropositivity is associated with foetal and lamb loss in primiparous ewes, and (ii) ewes will demonstrate seroconversion for $C$. burnetii indicating that ewes are reservoir for infection.

\section{Methods}

All procedures were conducted according to guidelines of the Australian Code of Practice for the Use of Animals for Scientific Purposes and were approved by the Murdoch University Animal Ethics Committee (R3004/17).

\subsection{Animals and research sites}

This cross-sectional study was conducted at 28 farms using 30 study flocks located in Western Australia $(n=11)$, South Australia $(n=9)$, and Victoria $(n=10)$ between 2018 and 2020 (Figure 1; Supplementary File 1). Farms were selected based on convenience sampling, with eligibility for inclusion based on the farm having sufficient number of maiden ewes available for the study, capacity to monitor ewes and their progeny over the study period, and sheep genotype and management that were generally representative of standard commercial sheep farms in the region. Approximately two-hundred primiparous ewes at each farm were randomly selected at mating. All farms ran self-replacing flocks and ewes included in the study were managed according to standard farm practice.

\section{[INSERT FIGURE 1]}

\subsection{Animal measurements and sample collection}

Primiparous ewes were monitored between mating and lamb marking. Ewes were mated as either ewe lambs (7-10 months, $n=19$ flocks) or primiparous yearling ewes (18-20 months, $n=11$ flocks). Foetal mortality was determined via sequential transabdominal pregnancy ultrasounds at 62-101 days (scan 1) and 108-136 days (scan 2) from the start of mating. Lamb mortality between birth and marking were determined for each ewe based on birth type (single, twin or triplet), birth status (lambs dead or alive at lambing rounds) and survival status (lambs dead or alive) at marking which was approximately six weeks from the start of lambing. Ewe lactation status (lactating or non-lactating) was also determined at lamb marking.

Blood samples were collected from primiparous ewes by jugular venepuncture at pre-mating, scan 1 , scan 2, pre-lambing and lamb marking. At each farm, 20 multiparous ewes aged three years or older that had been bred and reared on the same farm were also randomly selected for collection of blood samples. 
Timing of sampling relative to lambing and the reproductive outcome for pregnancy was not recorded for multiparous ewes (Supplementary File 2). Blood samples were collected into serum vacutainer tubes with clot activator and stored on ice. Blood samples were centrifuged at $4000 \mathrm{rpm}$ for 10 minutes within 72 hours of collection. Serum was then decanted into $1 \mathrm{~mL}$ storage tubes and stored at $-20^{\circ} \mathrm{C}$ prior to serological testing.

\subsection{Serology}

A sub-sample of at least 40 primiparous ewes from each study flock were selected for $C$. burnetii serology (Supplementary File 1). Where possible, selection was based on ewes that were identified as pregnant at scan 1 but failed to successfully rear a lamb. This included ewes that aborted as well as ewes for which lamb mortality occurred in the perinatal period. Ewes that had reared single or twin lambs were included for flocks with less than 40 ewes that failed to rear a lamb (Supplementary File 1). Blood samples collected from primiparous ewes at lamb marking were used for serological screening except where not available, in which case samples from the latest available timepoint were screened instead. All blood samples collected from the multiparous ewes were used for serological screening (Supplementary File 2).

Anti-C. burnetii IgG serology were determined by VETPATH Laboratories (Perth, Western Australia) using a commercial indirect ELISA kit (ID Screen Q-Fever Indirect Multispecies, ID Vet, France) according to the manufacturer's instructions. The results were read at $450 \mathrm{~nm}$ using a Multiskan FC, Thermo Scientific spectrophotometer. Each plate included positive and negative internal controls. Optical density (OD) values were expressed as the mean percentage of sample/positive (S/P) values, as recommended by the manufacturer: $S / P$ value $=\left(O D_{\text {sample }}-O D_{\text {negative.control }}\right) /\left(O D_{\text {positive control }}-O D_{\text {negative.control }}\right)$. Serum samples were classified as positive ( $\mathrm{S} / \mathrm{P}$ value $\geq 50)$, doubtful ( $\mathrm{S} / \mathrm{P}$ value 40 to $<50$ ) or negative (S/P value $<40$ ) according to the manufacturer's recommendation. Lurier, Rousset, Gasqui, Sala, Claustre, Abrial, Dufour, de Crémoux, Gache, Delignette-Muller, Ayral and Jourdain [25] reported this indirect ELISA kit to have median sensitivity $86.9 \%$ (95\% credible interval (Crl) $71.2 \%, 93.6 \%$ ) and specificity $98.5 \%$ (95\% Crl 97.3\%, 99.4\%) for sheep.

For cases that returned positive or doubtful results using indirect ELISA, samples were re-tested with the same indirect ELISA as describe above, plus a complement fixation test (CFT) to determine the end-point titre. The CFTs were performed on serum by Department of Primary Industry and Regional Development Diagnostic Laboratory Service using methodology previously described by Ellis and Barton [26]. For the CFT, a serum tire of 1:8 or higher was considered positive [26]. Samples that returned one 'positive' result for either test were considered positive. Both laboratories used are NATA (National Association of Testing Authorities) accredited under ISO 17025 for veterinary testing.

\subsection{Aborted and stillborn tissues}

Tissue samples from aborted $(n=2)$ or stillborn $(n=33)$ lambs recovered from 6 flocks of primiparous ewes in Western Australia were submitted to the Department of Primary Industry and Regional Development Diagnostic Laboratory Services (Perth, Western Australia) and screened for $C$. burnetii using 
qPCR as previously described in more detail by Clune, Besier, Hair, Hancock, Lockwood, Thompson, Jelocnik and Jacobson [27].

\subsection{Statistical analyses}

Lamb mortality was calculated based on the number of foetuses identified at scan 1 and the number of lambs marked. Lamb mortality was classified as 'abortion' based on foetal loss between scan 1 and scan 2 (and validated with lambing records and ewe lactation status). Apparent $C$. burnetii seroprevalence was calculated using number positive samples as a proportion of samples tested, with $95 \%$ confidence interval was determined using Jeffreys method [28]. Apparent seroprevalence were compared for the primiparous ewe lambs, primiparous yearling ewes and multiparous ewes using a 2-tailed z-test.

The true prevalence and $95 \%$ credible intervals $(95 \% \mathrm{Crl})$ was estimated using Bayesian inference, considering the sensitivity and specificity and their $95 \%$ Crl derived from Lurier, Rousset, Gasqui, Sala, Claustre, Abrial, Dufour, de Crémoux, Gache, Delignette-Muller, Ayral and Jourdain [25] as beta-pert distribution for priors [29].

\section{Results}

\subsection{Reproductive performance of primiparous ewes}

Abortion between scan 1 and scan 2 was identified in 14/19 primiparous ewe lamb flocks and 6/11 primiparous yearling flocks. Abortion incidence in the ewe lamb flocks was greater than $2 \%$ for $6 / 19$ flocks and ranged $0-48.4 \%$ foetuses scanned. For the primiparous yearling flocks, abortion incidence was greater than $2 \%$ in $1 / 11$ flocks and ranged $0-3.7 \%$ foetuses scanned. Overall, foetus/lamb mortality between scan 1 and lamb marking ranged from $14.3-71.1 \%$ for ewe lambs and $19.7-52.7 \%$ for yearlings.

\subsection{Coxiella burnetii serology}

Overall apparent $C$. burnetii seroprevalence using indirect ELISA was $0.16 \%(95 \% \mathrm{Cl} 0 \%, 0.44 \%)$ and estimated true prevalence was $0.1 \%(95 \% \mathrm{Crl} 0.0 \%, 0.3 \%)$ (Table 1). Apparent $C$. burnetii seroprevalence was $0.08 \%(95 \% \mathrm{Cl} 0.01 \%, 0.36 \%)$ in primiparous ewes and $0.36 \%(0.07 \%, 1.14 \%)$ in mature ewes. Seroprevalence did not differ between primiparous ewes and adult multiparous ewes $(P=0.174)$, nor between primiparous yearlings and ewe lambs $(P=0.165)$. Farm-level seroconversion (detected in at least one animal) was $10.7 \%$ (3/28) farms. Within flock seroprevalence for the flocks for which seroconversion was detected was 2.5\% for one primiparous ewe flock in South Australia, and $5 \%$ for one multiparous ewe flock each for Western Australia and Victoria.

All three samples with seroconversion detected using indirect ELISA were negative for $C$. burnetii by CFT (Supplementary File 3). 
Table 1

Apparent seroprevalence and estimated true prevalence for $C$. burnetii for primipiarous ewes mated as ewe lambs or yearlings and adult multiparous ewes (aged 3 years or older) from 28 Australian farms.

\section{Ewes sampled}

\begin{tabular}{|llllll|}
\hline & $\begin{array}{l}\text { Flocks } \\
(\mathrm{n})\end{array}$ & $\begin{array}{l}\text { Individual } \\
\text { ewes }(\mathrm{n})\end{array}$ & $\begin{array}{l}\text { Seropositive } \\
\text { samples }(\mathrm{n})\end{array}$ & $\begin{array}{l}\text { Apparent } \\
\text { seroprevalence } \\
\%(95 \% \mathrm{Cl})\end{array}$ & $\begin{array}{l}\text { Estimated true } \\
\text { prevalence } \\
\%(95 \% \mathrm{Crl})\end{array}$ \\
\hline $\begin{array}{l}\text { Primiparous } \\
\text { ewes }\end{array}$ & & & & & \\
\hline Ewe lambs & 19 & 839 & 0 & $0(0,0.30)$ & $0.1(0.0,0.4)$ \\
\hline Yearling & 11 & 440 & 1 & $0.23(0.02,1.06)$ & $0.3(0.0,1.1)$ \\
\hline Adults & 28 & 558 & 2 & $0.36(0.07,1.14)$ & $0.3(0.0,1.0)$ \\
\hline Overall & - & 1837 & 3 & $0.16(0.05,0.44)$ & $0.1(0.0,0.3)$ \\
\hline
\end{tabular}

95\% $\mathrm{Cl}: 95 \%$ confidence interval

95\% Crl: $95 \%$ credible interval

Molecular detection of $C$. burnetii in tissues from aborted and stillborn lambs

Coxiella burnetii was not detected by qPCR in tissue samples from aborted $(n=2)$ or stillborn lambs $(n=$ 33) recovered from primiparous ewes on the subset of six farms in Western Australia [27].

\section{Discussion}

There was no evidence to implicate $C$. burnetii as an important contributor to abortion or perinatal lamb mortality in 30 primiparous ewe flocks located across southern Australia. The very low $C$. burnetii seroprevalence was consistent with the absence of detection of $C$. burnetii in tissues from aborted or stillborn lambs from a subset of farms. These findings are consistent with recent reviews of veterinary laboratory investigations that reported coxiellosis to be an uncommon diagnosis in Australian sheep abortion investigations $[5,6]$. Coxiella burnetii control programs such as routine vaccination of breeding ewes are not warranted for sheep farms in southern Australia in the absence of further evidence that coxiellosis is contributing to lamb mortality. Nonetheless, $C$. burnetii should continue to be included in sheep abortion and perinatal mortality investigation protocols due to the sporadic nature of disease and important zoonotic implications.

This was an observational study with sheep managed extensively, reflecting standard sheep management in these regions of Australia. Although foetal and lamb mortality between scanning and lamb marking were high for some flocks, average lamb mortality in the primiparous flocks was consistent with ranges previously reported in Australian studies [30]. It is unclear from the current study whether 
reproductive performance of maiden ewes would be impacted in flocks where seroprevalence was greater.

Serological testing targeted primiparous ewes with evidence of abortion and perinatal lamb mortality. Bias towards ewes that failed to rear lambs could be expected to overestimate prevalence in the general sheep population if $C$. burnetii was an important contributor to abortion and perinatal deaths. Blood samples for primiparous ewe samples were collected close to the time of lambing or abortion, and this may increase probability of detection for $C$. burnetii seroconversion [31]. Very low seroprevalence in this sampled population suggests that coxiellosis was not an important contributor to abortion and perinatal lamb mortality in these flocks and was consistent with very low seroprevalence in adult ewes on these farms.

This is the most geographically widespread seroprevalence study for $C$. burnetii in Australian sheep. Very low $C$. burnetii seroprevalence was consistent with previous studies from Western Australia [18] and Victoria [7] that reported individual seroprevalence ranging from $0-4.1 \%$, and flock-level seroprevalence ranging from $0-17.6 \%$. Our study did not include sheep flocks from New South Wales, Queensland or Tasmania. New South Wales and Queensland have the highest rates of human Q-fever reported in Australia [20]. The most recent studies reporting $C$. burnetii prevalence in sheep from New South Wales and Queensland are considerably dated and involve either single farms $[15,16]$ or abattoir surveys [17]. Increased incidence of local acquisition of human infection may be associated with high prevalence in livestock [32]. Hence, investigation of $C$. burnetii seroprevalence in sheep from New South Wales and Queensland is warranted.

Sampling younger ewes likely contributed to the low $C$. burnetii seroprevalence reported in this study. Age is recognised as an important risk factor for $C$. burnetii seropositivity, with older animals more likely to be seropositive [33-35]. Notwithstanding this, no apparent difference in seroprevalence was observed between primiparous ewe lambs (approximately 13 months old at lambing), yearlings ( 2 years old at lambing) and mature ewes (3 years or older).

There is no reference test for serological diagnosis of coxiellosis, and sensitivity and specificity for $C$. burnetii serological tests are not well described [36]. The commercial indirect ELISA for $C$. burnetii that was used in this study has been used in other seroprevalence studies in sheep [25,36-40] and the World Organisation for Animal Health (OIE) recommends ELISA as the preferred method for $C$. burnetii seroprevalence studies [41]. In our study, the three samples categorised as seropositive using indirect ELISA were negative by CFT. It was not possible to determine if these were false positives. Complement fixation tests are reported to have lower sensitivity than ELISA, but high specificity for elevated levels of anti- $C$. burnetii antibodies in flocks with $C$. burnetii-associated abortions [41]. Discordant results can be observed using different ELISA kits [42], therefore testing samples with more than one kit is an alternative option for validating animal status [41]. Validation for commercial ELISA in Australian sheep under field conditions could better inform estimation of true prevalence. However, coxiellosis is not frequently 
diagnosed in Australian sheep which presents challenges for evaluating assay sensitivity and specificity under field conditions.

Seroprevalence surveys may underestimate $C$. burnetii shedding in livestock. Banazis, Bestall, Reid and Fenwick [18] detected $C$. burnetii in Australian sheep faecal samples in the absence of $C$. burnetii seroconversion. Other studies have also demonstrated poor correlation between seroconversion and antigen detection [10, 12, 36, 43]. Joulié, Rousset, Gasqui, Lepetitcolin, Leblond, Sidi-Boumedine and Jourdain [36] reported good correlation between high $C$. burnetii burden on vaginal swabs and seroconversion one-month post-abortion or post-lambing using the same commercial indirect ELISA kit as used in our study. However, it is possible that some ewes in our study were shedding $C$. burnetii without evidence of seroconversion, and thus represent a reservoir of $C$. burnetii infection for other sheep or humans. Nevertheless, the combination of testing methodology used and timing of blood sample collection (within 6 weeks of parturition) in conjunction with the absence of detection of $C$. burnetii using molecular techniques on tissues from aborted or stillborn lambs suggests that coxiellosis was not a major contributor to abortion and lamb mortality observed on these farms.

Despite low seroprevalence detected in this study, contact with sheep should still be considered a risk factor for Q-fever in humans and precautions should be taken to reduce the risk of zoonotic $C$. burnetii transmission. Sheep have been associated with cases of Q-fever in humans in Australia and overseas $[10,15,32,44-48]$. Coxiella burnetii shedding can occur from both symptomatic and asymptomatic sheep, and in the absence of detectable seroconversion $[49,50]$. Control strategies include use of appropriate personal protective clothing when handling birth material or lambing ewes, good hygiene practices, controlling dust and vaccination of people with an occupational risk including farm, abattoir and veterinary staff.

\section{Conclusion}

There was no evidence to implicate $C$. burnetii as an important contributor to abortions or perinatal lamb mortality observed for primiparous ewes on the farms in this study. Furthermore, exposure to $C$. burnetii was not widespread in sheep from farms in southern Australia included in the study. Whilst ewes on these farms were not an important reservoir for $C$. burnetii, the occupational risk associated with transmission of $C$. burnetii from Australian sheep has public health implications and people at risk should maintain appropriate measures to avoid zoonotic transmission.

\section{Declarations}

\section{Acknowledgments}

We thank the participating farmers who provided access to their animals and facilities, conducted lambing rounds, and collected and stored lambs for necropsy. We thank Celia Smuts, Janine Simmonds and the staff at VetPath for their assistance with the serological testing. We thank Shane Besier, Sam 
Hair, Cameron Loomes, Richmond Loh and Anna Erickson at DPIRD for their assistance with the laboratory diagnostic testing through the DPIRD Abortion Surveillance Scheme. We thank Tom La and Nyree Phillips for their assistance with sample collection.

\section{Funding}

This study was funded by Meat and Livestock Australia (B.AHE.0318). The manuscript was approved for publication by the funding body (Meat and Livestock Australia), but Meat and Livestock Australia was not involved in the collection, analysis or interpretation of data, or in the writing of the manuscript. Molecular diagnostic testing for aborted and stillborn lambs was performed under the Western Australian Ewe Abortion and Newborn Lamb Death Surveillance Program (Department of Primary Industries and Regional development, Western Australia). Tom Clune received post-graduate scholarships from Meat and Livestock Australia and Sheep Industry Business Innovation (Department of Primary Industries and Regional Development, Western Australia). Equipment used for this project was funded by the Murdoch University Veterinary Trust.

\section{Declaration of interest}

None of the authors of this paper have a financial or personal relationship with other people or organisations that could inappropriately influence or bias the content of the paper.

\section{References}

1. P.R. Shorten, S.J. Edwards, J.L. Juengel, The role of reproductive loss on flock performance: a comparison of nine industry flocks, Transl. Anim. Sci. 5(1) (2021) txab013-txab013.

2. M.B. Allworth, H.A. Wrigley, A. Cowling, Fetal and lamb losses from pregnancy scanning to lamb marking in commercial sheep flocks in southern New South Wales, Anim. Prod. Sci. 57(10) (2017) 2060-2065.

3. D.O. Kleemann, S.K. Walker, Fertility in South Australian commercial Merino flocks: sources of reproductive wastage, Theriogenology 63(8) (2005) 2075-2088.

4. R. Kilgour, Lambing potential and mortality in Merino sheep as ascertained by ultrasonography, Aust. J. Exp. Agric. 32(3) (1992) 311-313.

5. G. Refshauge, T. Atkinson, S.M. Robertson, M. Hernandez-Jover, B. Allworth, M. Friend, Reducing Kid Loss - Select and Project. Phase 1 Final report, Meat and Livestock Australia, North Sydney, Australia. https://www.mla.com.au/research-and-development/reports/2020/reducing-kid-lossselect-and-protect--phase-1/ Accessed 1 February, 2021, 2020.

6. T. Clune, S. Beetson, S. Besier, G. Knowles, R. Paskin, G. Rawlin, R. Suter, C. Jacobson, Ovine abortion and stillbirth investigations in Australia, Aust. Vet. J. 99(3) (2021) 72-78. 
7. T. Tan, A pilot study of the seroprevalence of Q fever in cattle, sheep and goats in Victoria (embargo October 2020), University of Melbourne, 2018.

8. N. Arricau-Bouvery, A. Rodolakis, Is Q fever an emerging or re-emerging zoonosis?, Vet. Res. 36(3) (2005) 327-349.

9. S.P. Martinov, P. Neikov, G.V. Popov, Experimental Q Fever in Sheep, Eur. J. Epidemiol. 5(4) (1989) 428-431.

10. M. Berri, A. Souriau, M. Crosby, D. Crochet, P. Lechopier, A. Rodolakis, Relationships between the shedding of Coxiella burnetii, clinical signs and serological responses of 34 sheep, Vet. Rec. 148(16) (2001) 502-505.

11. D.L. Brooks, R.W. Ermel, C.E. Franti, R. Ruppanner, D.E. Behymer, J.C. Williams, E.H. Stephenson, J.C. Stephenson, Q fever vaccination of sheep: challenge of immunity in ewes, Am. J. Vet. Res. 47(6) (1986) 1235-1238.

12. M. Berri, D. Crochet, S. Santiago, A. Rodolakis, Spread of Coxiella burnetii infection in a flock of sheep after an episode of Q fever, Vet. Rec. 157(23) (2005) 737-740.

13. J.S. Agerholm, Coxiella burnetii associated reproductive disorders in domestic animals--a critical review, Acta Vet. Scand. 55(1) (2013) 13-13.

14. M. Berri, E. Rousset, J.L. Champion, P. Russo, A. Rodolakis, Goats may experience reproductive failures and shed Coxiella burnetii at two successive parturitions after a $\mathrm{Q}$ fever infection, Res. Vet. Sci. 83(1) (2007) 47-52.

15. E.H. Derrick, J.H. Pope, D.J. Smith, Outbreak of Q fever in Queensland associated with sheep, Med. J. Aust. 46(18) (1959) 585.

16. I.D. Smith, Reproductive wastage in a Merino flock in central western Queensland, Aust. Vet. J. 38(10) (1962) 500-507.

17. L.C. Rowan, J.C. Keast, Q Fever antibodies in New South Wales sheep, Aust. Vet. J. 41(11) (1965) 356-359.

18. M.J. Banazis, A.S. Bestall, S.A. Reid, S.G. Fenwick, A survey of Western Australian sheep, cattle and kangaroos to determine the prevalence of Coxiella burnetii, Vet. Microbiol. 143(2) (2010) 337-345.

19. H.F. Gidding, C. Wallace, G.L. Lawrence, P.B. McIntyre, Australia's national Q fever vaccination program, Vaccine 27(14) (2009) 2037-2041.

20. K. Eastwood, S. Graves, P. Massey, K. Bosward, D. van den Berg, P. Hutchinson, Q Fever, Aust. J. Gen. Pract. 47 (2018) 5555-5555.

21. P.E. Fournier, T.J. Marrie, D. Raoult, Diagnosis of Q fever, J. Clin. Microbiol. 36(7) (1998) 1823-1834.

22. E. Angelakis, D. Raoult, Q fever, Vet. Microbiol. 140(3) (2010) 297-309.

23. T.S. Sloan-Gardner, P.D. Massey, P. Hutchinson, K. Knope, E. Fearnley, Trends and risk factors for human Q fever in Australia, 1991-2014, Epidemiology and Infection 145(4) (2016) 1-9.

24. K.A. Bond, G. Vincent, C.R. Wilks, L. Franklin, B. Sutton, J. Stenos, R. Cowan, K. Lim, E. Athan, O. Harris, L. Macfarlane-Berry, Y. Segal, S.M. Firestone, One Health approach to controlling a Q fever 
outbreak on an Australian goat farm, Epidemiol. Infect. 144(6) (2016) 1129-1141.

25. T. Lurier, E. Rousset, P. Gasqui, C. Sala, C. Claustre, D. Abrial, P. Dufour, R. de Crémoux, K. Gache, M.L. Delignette-Muller, F. Ayral, E. Jourdain, Evaluation using latent class models of the diagnostic performances of three ELISA tests commercialized for the serological diagnosis of Coxiella burnetii infection in domestic ruminants, Vet. Res. 52(1) (2021) 56.

26. T.M. Ellis, M.D. Barton, Australia and New Zealand Standard Diagnostic Procedures: Q fever, Australian Government, The Department of Agriculture and Water Resources, 2003, pp. 1-7.

27. T. Clune, S. Besier, S. Hair, S. Hancock, A. Lockwood, A. Thompson, M. Jelocnik, C. Jacobson, Chlamydia pecorum detection in aborted and stillborn lambs from Western Australia, Vet. Res. 52(1) (2021) 84.

28. L.D. Brown, T.T. Cat, A. DasGupta, Interval estimation for a proportion, Stat. Sci. 16(101-133) (2001).

29. N. Speybroeck, B. Devleesschauwer, L. Joseph, D. Berkvens, Misclassification errors in prevalence estimation: Bayesian handling with care, Int J Public Health 58(5) (2013) 791-5.

30. G.N. Hinch, F. Brien, Lamb survival in Australian flocks: a review, Anim. Prod. Sci. 54(6) (2014) 656.

31. M. Muleme, J. Stenos, G. Vincent, C.R. Wilks, J.M. Devlin, A. Campbell, A. Cameron, M.A. Stevenson, S. Graves, S.M. Firestone, Peripartum dynamics of Coxiella burnetii infections in intensively managed dairy goats associated with a Q fever outbreak in Australia, Prev. Vet. Med. 139(Pt A) (2017) 58-66.

32. K.A. Bond, L. Franklin, B. Sutton, M.A. Stevenson, S.M. Firestone, Review of 20 years of human acute Q fever notifications in Victoria, 1994-2013, Aust. Vet. J. 96(6) (2018) 223-230.

33. M. Klaassen, H.-J. Roest, v.d.W. Hoek, B. Goossens, A. Secka, A. Stegeman, Coxiella burnetii seroprevalence in small ruminants in The Gambia, PLoS One 9(1) (2014) e85424-e85424.

34. J. Muema, S.M. Thumbi, M. Obonyo, S. Wanyoike, M. Nanyingi, E. Osoro, A. Bitek, S. Karanja, Seroprevalence and factors associated with Coxiella burnetii infection in small ruminants in Baringo County, Kenya, Zoonoses Public Health 64(7) (2017) e31-e43.

35. A.L. García-Pérez, I. Astobiza, J.F. Barandika, R. Atxaerandio, A. Hurtado, R.A. Juste, Short communication: Investigation of Coxiella burnetii occurrence in dairy sheep flocks by bulk-tank milk analysis and antibody level determination, J. Dairy Sci. 92(4) (2009) 1581-1584.

36. A. Joulié, E. Rousset, P. Gasqui, E. Lepetitcolin, A. Leblond, K. Sidi-Boumedine, E. Jourdain, Coxiella burnetii Circulation in a Naturally Infected Flock of Sheep: Individual Follow-Up of Antibodies in Serum and Milk, Applied and Environmental Microbiology 83(13) (2017) e00222-17.

37. R. Cruz, F. Esteves, C. Vasconcelos-Nóbrega, C. Santos, A.S. Ferreira, C. Mega, A.C. Coelho, H. Vala, J.R. Mesquita, A Nationwide Seroepidemiologic Study on Q Fever Antibodies in Sheep of Portugal, Vector-Borne and Zoonotic Diseases 18(11) (2018) 601-604.

38. S. Villari, P. Galluzzo, M. Arnone, M. Alfano, F. Geraci, G. Chiarenza, Seroprevalence of Coxiella burnetii infection (Q fever) in sheep farms located in Sicily (Southern Italy) and related risk factors, Small Rumin. Res. 164 (2018) 82-86. 
39. A. Conan, A.A.M.J. Becker, V. Alava, A. Chapwanya, J. Carter, K. Roman, H. Avsaroglu, C.A. Gallagher, Detection of Coxiella burnetii antibodies in sheep and cattle on a veterinary campus in St. Kitts: Implications for one health in the Caribbean region, One Health 10 (2020) 100163.

40. M.-È. Turcotte, S. Buczinski, A. Leboeuf, J. Harel, D. Bélanger, D. Tremblay, C.A. Gagnon, J. Arsenault, Epidemiological study of Coxiella burnetii in dairy cattle and small ruminants in Québec, Canada, Prev. Vet. Med. 191 (2021) 105365.

41. World Organisation for Animal Health, Q fever (chapter 3.1.16), Manual of Diagnostic Tests and Vaccines for Terrestrial Animals 2019, World Organisation for Animal Health (OIE), Available: https://www.oie.int/en/what-we-do/standards/codes-and-manuals/terrestrial-manual-online-access/ (accessed June 2021), 2019.

42. M.W. Horigan, M.M. Bell, T.R. Pollard, A.R. Sayers, G.C. Pritchard, Q fever diagnosis in domestic ruminants: comparison between complement fixation and commercial enzyme-linked immunosorbent assays, J. Vet. Diagn. Invest. 23(5) (2011) 924-31.

43. N. Arricau Bouvery, A. Souriau, P. Lechopier, A. Rodolakis, Experimental Coxiella burnetii infection in pregnant goats: excretion routes, Vet. Res. 34(4) (2003) 423-433.

44. S.R. Graves, A. Islam, Endemic Q Fever in New South Wales, Australia: A case series (2005-2013), American Journal of Tropical Medicine and Hygiene 95(1) (2016) 55-59.

45. P.J. Boland, N.R. Parker, Q fever in south west Queensland, Med. J. Aust. 171(8) (1999) 446-446.

46. B.A. O'Connor, I.G. Tribe, R. Givney, A windy day in a sheep saleyard: an outbreak of Q fever in rural South Australia, Epidemiol. Infect. 143(2) (2015) 391-398.

47. H. Tissot-Dupont, M.-A. Amadei, M. Nezri, D. Raoult, Wind in November, Q Fever in December, Emerg. Infect. Dis. 10(7) (2004) 1264-1269.

48. D. Webster, D. Haase, T.J. Marrie, N. Campbell, J. Pettipas, R. Davidson, T.F. Hatchette, Ovineassociated Q fever, Epidemiol. Infect. 137(5) (2009) 744-751.

49. R.M. Jones, D.F. Twomey, S. Hannon, J. Errington, G.C. Pritchard, J. Sawyer, Detection of Coxiella burnetii in placenta and abortion samples from British ruminants using real-time PCR, Vet. Rec. 167(25) (2010) 965-967.

50. A. Rodolakis, M. Berri, C. Héchard, C. Caudron, A. Souriau, C.C. Bodier, B. Blanchard, P. Camuset, P. Devillechaise, J.C. Natorp, J.P. Vadet, N. Arricau-Bouvery, Comparison of Coxiella burnetii shedding in milk of dairy bovine, caprine, and ovine Herds, J. Dairy Sci. 90(12) (2007) 5352-5360.

51. Australian Government Bureau of Meteorology, Australian Climate Averages - Rainfall, 2021. http://www.bom.gov.au/jsp/ncc/climate_averages/rainfall/index.jsp. (Accessed June 2021 2021).

\section{Figures}




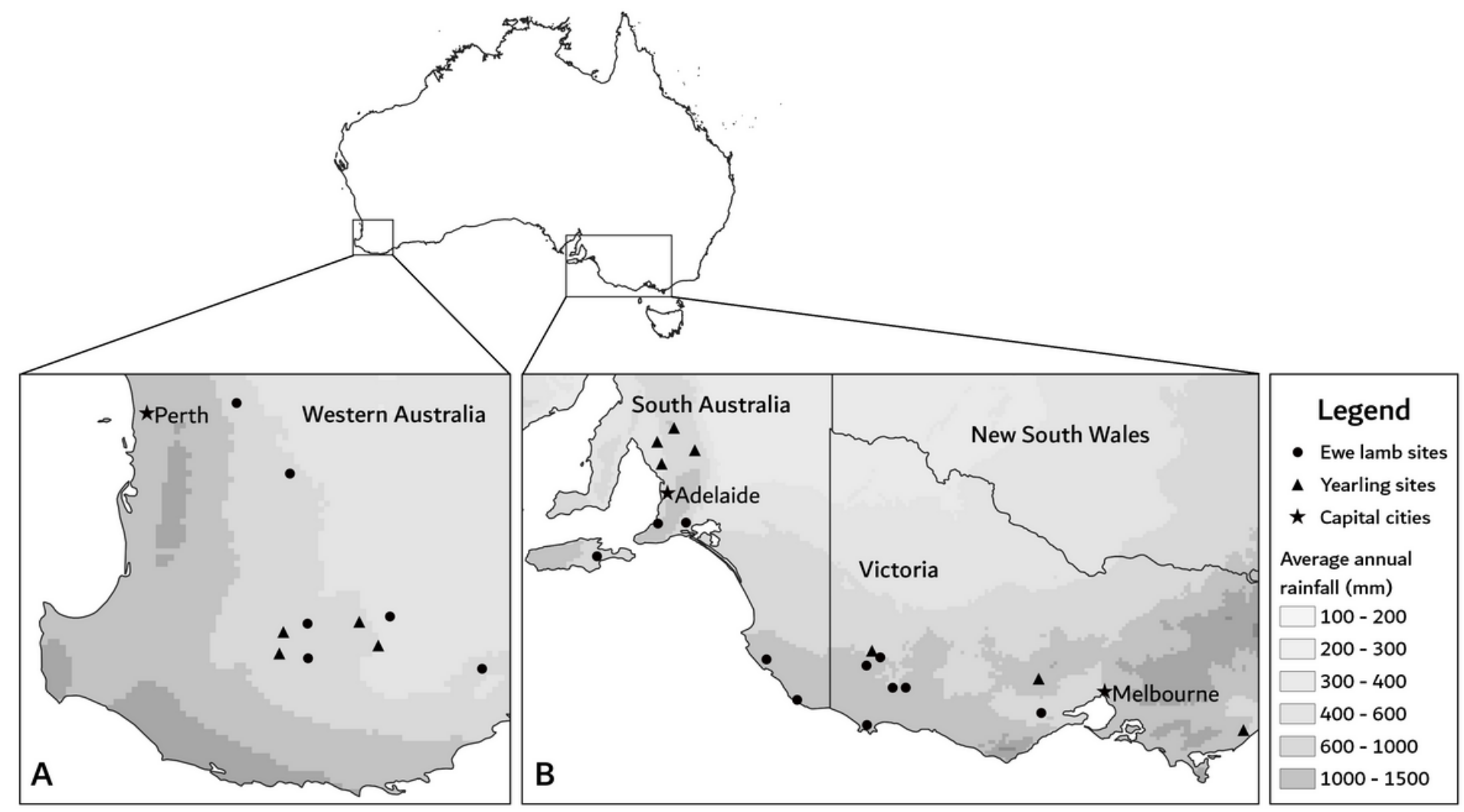

\section{Figure 1}

Location of sheep farms sampled in Western Australia (Map A), and South Australia and Victoria (Map B). Average annual rainfall data sourced from Australian Government Bureau of Meteorology [51]

\section{Supplementary Files}

This is a list of supplementary files associated with this preprint. Click to download.

- Suppfile1.pdf

- Suppfile2.pdf

- Suppfile3.pdf 